\title{
A GOVERNANÇA ELETRÔNICA INSERIDA NO ORÇAMENTO PARTICIPATIVO VIRTUAL
}

\author{
F. L. F. COSTA* e J. P. MEDEIROS \\ Instituto Federal de Educação, Ciência e Tecnologia do Rio Grande do Norte \\ nardinho_Ip@hotmail.com
}

Artigo submetido em março/2016 e aceito em agosto/2016

DOI: 10.15628/empiricabr.2016.4253

\section{RESUMO}

A presente pesquisa possui como objetivo geral analisar o Orçamento Participativo Virtual como um mecanismo de governança eletrônica da gestão municipal da cidade do Natal/RN. No referencial teórico foram abordados os tópicos - governo eletrônico, governança eletrônica e Orçamento Participativo, nos quais comtemplam a inserção das Tecnologias da Informação e Comunicação (TIC) no ambiente das políticas públicas, trazendo como principais autores - Frey, Rezende (2005) e Ruediger (2002). A construção do presente estudo deu-se por meio de uma abordagem qualitativa, na captação dos dados primários, por meio da elaboração do instrumento de coleta de dados. Além disso, a linha de pesquisa dá-se por meio de um estudo exploratório, na qual guia-se através de uma problemática. Soma-se ainda, o envolvimento descritivo, por permitir análise, registros e interpretação de um instrumento, com a finalidade de observar o sistema do Orçamento Participativo Virtual (OPV). Dessa forma, a pesquisa desenvolveu-se por meio de um estudo de caso único, com fomento na integração entre a população e a gestão na utilização de um sistema de informação gerencial - Orçamento Participativo. Por meio do desenvolvimento do presente estudo, concluiuse que o OPV pode servir como minimizador de custos, com plenárias e eventos, flexibilizando o processo. Por fim, verificou-se a contribuição direta do OPV na ampliação da participação da sociedade na gestão e controle das necessidades demandadas. Gerando assim, maior satisfação da população e aplicação eficiente dos recursos disponíveis.

PALAVRAS-CHAVE: Governança Eletrônica; Orçamento Participativo Virtual; Integração.

\section{E-GOVERNANCE WITHIN THE PARTICIPATORY BUDGET VIRTUAL}

\begin{abstract}
This research has as main objective to analyze the Participatory Budget as a Virtual electronic governance mechanism of the municipal administration of the city of Natal / RN. In theoretical topics were addressed - egovernment, e-governance and participatory budgeting, in which comtemplam the inclusion of Information and Communication Technologies (ICT) in the public policy environment, bringing as main authors - Frey, Rezende (2005) and Ruediger (2002). The construction of this study was given by means of a qualitative approach, the capture of primary data through the elaboration of the data collection instrument. Moreover, the search line occurs by means of an exploratory study, in which is guided through a problem. Added to the descriptive
\end{abstract}

involvement by allowing analysis, recording and interpretation of an instrument, in order to observe the system Virtual Participatory Budget (OPV). Thus, the research was developed through a unique case study, to promote the integration of population and management in the use of a management information system Participatory Budgeting. Through development of this study, it was concluded that the OPVs may serve as minimizing cost, and with plenary events, easing the process. Finally, there was the direct contribution of OPV in expanding the participation of society in the management and control of the needs required. Thus generating greater satisfaction of the population and efficient use of available resources.

KEYWORDS: E-Governance; Participatory Budgeting; Integration. 


\section{INTRODUÇÃO}

A internet é uma ferramenta que oferece a possibilidade de uma grande coleta de dados, que de forma rápida e simples, atinge a todos aqueles que dela se beneficiam, fazendo-o desse recurso um componente democratizador. $\mathrm{O}$ atrelamento desse meio de comunicação ao ambiente político gera soluções para os problemas vividos pela população, dispensando a utilização e recursos direcionados aos intermediários, o que minimiza os custos e otimiza as pesquisas, abrangendo um maior público.

Diversos autores consideram a internet um incentivador da participação popular. Enquanto instituições territoriais tradicionais, tiveram seu momento rígido e hierárquico na sua utilização, não existindo democracia em seu uso. Em contraponto ao atual momento, a internet privilegia modos de relacionamento transversais e estruturas mais fluidas, mais alinhadas com as estruturas de rede que caracterizam os processos sociais e políticos nas sociedades democráticas modernas. O potencial democrático específico da Internet baseia-se em sua estrutura não-hierárquica e cibernética que, em princípio, favorece a interatividade (FREY, 2000)

Nesse ambiente, conta-se com a facilidade de acesso, uma vez que o cidadão pode participar de qualquer ambiente que contenha acesso à internet; e também com a rapidez na participação da pesquisa, gerando o aumento no número de retornos. Assim, a população tem a chance de participar ativamente de todo o processo (social e político), opinando ou informando sobre possíveis relações que estão em desacordo com o processo. Todo esse sistema gera maior interação entre Estado e sociedade, beneficiando o processo como um todo.

De acordo com Frey (2000), diversos pesquisadores desenvolvem os seus estudos em acordo com a interação que a internet proporciona, atribuindo forte potencial com instituições governamentais. Ou seja, essa interação pode ser usada em ambiente público, tornando-os mais personalizados e direcionados ao povo, que em conjunto pode vir a criar novas formas democráticas, aumentando ainda mais as relações entre Estado e população. Além disso, tal uso da internet é tanto tratado como governo eletrônico (CHADWICK, 2003; JAEGER, 2005) quanto governança eletrônica (FREY, 2000; FREY; REZENDE, 2005).

Nesse projeto, ambiciona-se compreender e auxiliar um pouco mais a respeito da participação da população frente os assuntos políticos. Dessa forma, traz a importância e contribuição que o Orçamento Participativo Virtual direciona ao entorno em benefício da população.

Desenvolvido pela Secretaria Municipal de Planejamento (SEMPLA) do município de Natal, o Orçamento Participativo Virtual (OPV) entrou em funcionamento no dia 30 de setembro de 2014, por meio de uma ferramenta do Google Drive, com o objetivo de aumentar e democratizar a participação popular na gestão da capital potiguar.

O OPV tem como objetivo maior atingir a parcela da população que não participa presencialmente das atividades do Orçamento Participativo, como por exemplo, os jovens e os estudantes do ensino médio e superior. E, segundo dados prévios do Departamento de Planejamento e Participação Popular da SEMPLA, o objetivo tem sido alcançado.

Os primeiros dados do OPV mostram que a maior participação, no que se refere à escolaridade, está nos indivíduos com nível superior completo (45\%) e nos ainda em formação 
(29\%); os com nível médio completo e incompleto representam $17 \%$ e $4 \%$ respectivamente, totalizando $95 \%$ (os $5 \%$ restantes sem enquadram na população com ensino fundamental completo e incompleto). Quanto a esses dados, não é possível fazer comparação com a população que participa presencialmente das ações do OP, haja vista não terem sido coletadas informações referentes ao nível de formação das pessoas.

Outros indicadores foram modificados por meio do OPV, como o da participação por gênero e região administrativa. Nas atividades presenciais, o percentual de participação das mulheres foi superior ao dos homens, elas representando 59,4\% dos participantes, e eles, 40,6\%; já no virtual, até o dia 10 de novembro de 2014, as mulheres representavam $42 \%$ dos participantes e os homens, $58 \%$.

Quanto à representação regional nas atividades presenciais do OP, a região Sul e Leste são as menos representativas, com $20 \%$ e $9,6 \%$ respectivamente; a região Oeste lidera com $42,8 \%$, seguido da região Norte com 27,6\%; já no OPV, a região Sul mostra-se mais participativa do que as demais regiões, chegando a representar $41 \%$ dos participantes. Porém, a região Leste continua pouco representada, com $11 \%$. A região Norte fica em segundo lugar com $32 \%$, e a região Oeste aparece em terceiro, com $16 \%$.

Com a finalização de todo o processo participativo no ano 2014, será possível a obtenção de novos dados referentes à participação popular na formulação da agenda governamental do município de Natal. O que se pode dizer de início é que as atividades presenciais do OP e o Orçamento Participativo Virtual têm atingindo públicos diferentes, favorecendo e fortalecendo a democracia participativa.

Diante do exposto sobre a interação do Estado e população frente o Orçamento Participativo, pretende-se compreender como o Orçamento Participativo Virtual pode servir a gestão municipal da cidade do Natal/RN como um mecanismo de governança eletrônica. Buscando ainda, objetivar a análise do Orçamento Participativo como um mecanismo de governança eletrônica da gestão municipal da cidade do Natal/RN. Por meio disso, buscou-se analisar as contribuições dos munícipes em sua inserção do Orçamento Participativo Virtual; levantar o status de execução das ações e serviços deliberados pela população a partir do Orçamento Participativo; evidenciar as características fortes e fracas do processo de Orçamento Participativo Virtual no que diz respeito à promoção de valores democráticos; e avaliar o site do Orçamento Participativo Virtual do município do Natal/RN no que diz respeito ao ambiente informativo e às ferramentas participativas.

\section{REVISÃO BIBLIOGRÁFICA}

A pesquisa sobre Orçamento Participativo Virtual (OPV) compreende a integração da população, por meio de sistemas de informação com direcionamento a governança eletrônica.

\subsection{Governo eletrônico}

Governo eletrônico remete a um conceito abrangente, no qual as novas tecnologias de informação e comunicação são aplicadas às funções de governo, que podem visar a diferentes setores, ao cidadão ou ao mercado. Tem o potencial de diminuir custos, influenciar o desenvolvimento econômico, a redução de repetitivos erros na aplicação de políticas públicas, 
maior transparência e accountability e aprimorar serviços para os cidadãos como melhores condições de acesso à informação e a serviços governamentais, ampliando a qualidade destes serviços e garantindo maiores oportunidade de participação social no processo democrático (SAMPAIO, 2009).

Dentre as abordagens sobre a internet, com foco sobre governo eletrônico, alguns autores destacam ainda a linha, que tenderia a enfatizar a questão informacional ou clientelista, ou ainda, uma relação de cima para baixo - top-down - ou vertical entre representantes e representados, como relatado por Chadwick (2003); Dahlren (2005); Gomes (2005). Ainda nesta visão, os cidadãos pouco podem interferir no meio político. É a blindagem antipúblico caracterizada por Gomes (2005) e Bentivegna (2006) na qual o sistema político arma barreiras contra a participação dos cidadãos. Mesmo quando há ferramentas e possibilidades participativas e interativas, elas não são efetivamente capazes de alterar a lógica de tomada de decisões ou o funcionamento do sistema político.

O grande avanço das Tecnologias da Informação e Comunicação (TIC's) permite um governo mais próximo da população por meio da rede internet. Com isso, a informação pode ser utilizada para aperfeiçoar a administração e a política, fazendo assim que o cidadão influencie nas decisões da política pública através do ambiente virtual, objetivando as ferramentas disponibilizadas pelo governo. (CHADWICK, 2003).

Mantendo uma linha de raciocínio, um governo eletrônico bom seria aquele que conseguisse oferecer os melhores serviços ao cidadão e reduzir os custos estatais. O cidadão é considerado um cliente, onde o governo deve fornecer a ele os seus serviços. De forma mais branda, o uso dessas novas tecnologias poderia ser gerido mais agilmente e eficientemente quanto à entrega de serviços à população (SAMPAIO, 2009)

A outra linha de raciocínio, sugere caracterizar um governo eletrônico como uma espécie de experimento em construção. Diante disso, "considerando sua natureza eminentemente política, bem como pública, deve necessariamente ser percebido como um processo em constante desenvolvimento" (FREY, REZENDE, 2005, p. 55).

Ambas as linhas, sugerem um foco na participação da população para intervir diretamente no processo democrático expressando a vontade civil nas instâncias decisórias do Estado. (GOMES, 2005, JARDIM, 2004). Tanto uma, como outra linha, propõem profundas mudanças até mesmo na forma de administração, pois ambas as linhas apresentadas anteriormente passariam a ser interpostas por informações que a própria população forneceria. (CHADWICK, 2003). A partir disso, tende-se a confundir o conceito entre governo eletrônico e governança eletrônica, relatado no tópico seguinte, com fomento de esclarecimento.

\subsection{Governança eletrônica}

Ainda não há um consenso sobre o conceito de governança (CAPELLA, 2008), e isso irá se repetir na definição de governança eletrônica, que é um conceito que muitas vezes se confunde e diverge de outros como: governo eletrônico, tecnologias de informação e comunicação (TIC's), democracia eletrônica, participação eletrônica, entre outros. Isso significa que nenhum conceito é amplamente aceito ou refutado, e, portanto, a discussão e a ampliação do uso das TIC's pelos 
governos se iniciam na inexistência de um consenso sobre a definição do conceito de governança eletrônica, como demonstrado por Cunha (2005, p. 1):

Os termos governança eletrônica e democracia eletrônica, em muitos trabalhos, parecem se confundir ao de governo eletrônico. Ora são utilizados como sinônimos, ora como subconjuntos, e as fronteiras dos campos que o distinguem não ficam sempre claras.

As definições de governança eletrônica (e-governança) e governo eletrônico (e-governo) entram em conflito constantemente e até se confundem. Não é fácil caracterizar o limite de ambos ou pelo menos o início da e-governança, que pode aparecer como um estágio ou até mesmo uma parte do e-governo. "Seria um passo fundamental para uma gestão moderna e eficiente, porém, sobretudo efetivamente promotora de preferenciais democráticos na sociedade" (RUEDIGER, 2002, p.1), ou pode ser definido ainda por Jardim (2004, p. 6-7):

O termo e-governance (governança eletrônica) centra-se em uma visão ampla de governabilidade, sinalizando como opera, trabalha e se organiza a sociedade à qual o governo deve assegurar o acesso e a participação em diversas redes de informação. Possui um sentido mais amplo e abarca o conceito de e-government, o qual teria como foco as tarefas gerenciais que conduzem à interação cidadaniagoverno. Do ponto de vista estritamente tecnológico, o E-gov visaria o cidadão como um ponto a conectar dentro de uma rede, enquanto a governabilidade eletrônica asseguraria o acesso e participação dos cidadãos individual e coletivamente dentro das redes governamentais.

A governança eletrônica pode se assemelhar ou até complementar uma gestão na sua forma de conduzir seus planos de meta utilizando da sociedade como ferramenta base, pois corresponde ao processo ou ao modo de conduzir a população a melhorar e atingir seus interesses e metas através das ferramentas estatais que são disponibilizadas, e gerir até mesmo uma rearticulação entre Estado e sociedade (RIBEIRO FILHO; CARNEIRO, 2008).

Entretanto, as mudanças não implicam sempre no melhoramento dos serviços públicos para o cidadão. O que provavelmente resultaria em mudanças seria uma "governança social negociada", com algumas parcerias entre o público x privado e certos canais de participação popular; "a ênfase está no aumento de poder social, ou seja, a inclusão e o fortalecimento dos não poderosos nos processos de tomada de decisão política, enquanto que a eficiência administrativa é considerada um objetivo subordinado" (FREY, 2000, p. 35).

Para Frey (2005), as tecnologias da informação e comunicação permitem uma nova forma de participação democrática além de oferecer ferramentas que sugerem a criação de novos modelos de redes sociais e políticas, já que as redes sociais promovem uma relação transversal com estruturas mais fluídas, equivalente às estruturas de rede que especifica os processos políticos das sociedades modernas e os processos sociais.

Ruediger (2002) ainda apresenta uma proposta semelhante ao afirmar que se constitui um Estado virtual, extensão do real, facilitador das mudanças institucionais e capaz de promover um Estado para reinvenção do governo real. Isso, tanto pela articulação em rede dos diversos segmentos da administração, como pela introdução de mudanças estruturais do Estado, incluindo 
a transparência de processos e sua maior eficiência e permeabilidade, induzindo a uma reforma estrutural da esfera pública.

Entretanto, ambos os autores sabem que as transformações do Estado, não se darão exclusivamente pela inserção das TIC's no governo. A internet não foi criada apenas para promover a democracia, mas pelo seu grande acesso, ela tem potencialidade democrática, podendo ser usada assim para renovar os modos que a população participa, além de participar das decisões do governo (FREY, 2000). Mas, antes o Estado deve levar em conta os avanços tecnológicos e como fazer o uso de suas ferramentas tecnológicas, pois elas alteram os planos administrativos de governo, fazendo com que se tornem elementos fundamentais em suas estratégias de reformas administrativas desenvolvimento urbanos e a participação política em consonância com Frey; Rezende (2005, p. 10). Ruediger, (2002, p. 22), acrescenta ainda que;

A questão dos problemas da democratização e reestruturação do estado, passa pela superação da dicotomia entre membros do estamento de governo e sociedade civil, e pode ser alcançado no campo da utilização das novas mídias interativas, a partir de uma abertura planejada do projeto para a inclusão de percepções diversas, que organizadas, ampliem a responsabilidade dos sistemas e, mesmo, alterem sua relação hierárquica, promovendo mecanismos de participação nos processos de formulação e feedback da administração, transformando, notadamente, os mecanismos de serviços ad hoc de governo eletrônico em mecanismos políticos e sistêmicos de governança.

Com isso, a questão institucional não será o suficiente para a e-governança ser implementada, já que ela também depende da sociedade, pois é voltada para a mesma. Para Frey e Rezende (2005) - independentemente de afirmar que um Estado esteja engajado, disposto a ajudar, a permitir uma contribuição da população local para interferir nas tomadas de decisões, a mesma precisa ter uma vontade política para participar e confiar nas aplicações do governo em empregar as novas tecnologias para atingir os objetivos estabelecidos.

Apenas disponibilizar ferramentas on-line para a população utilizar não é o suficiente, é preciso que elas sejam efetivadas, que possam romper a blindagem antipúblico que Gomes (2005) e Bentivegna (2006) descrevem. Essas ferramentas têm que ter efeitos concretos no planejamento e desenvolvimento e ser capaz de influenciar nas decisões políticas. Alguns estudos sobre os programas participativos, em especial os Orçamentos Participativos (OP's) (AVRITZER, 2005, 2006), relatam existir uma relação direta entre efetividade dos processos em uma espécie de efeito demonstração com os índices de participação popular.

Diante disso, pode-se resumir em três pontos a governança política desejável. Primeiro é preciso vontade política, alguém que queira prover uma mudança no tradicionalismo hierárquico, fazendo com que a população participe através da internet, fazendo assim influenciar nas decisões. O segundo ponto, é que as informações sejam acessíveis, que a população possa acompanhar e monitorar as deliberações e obras em geral do Estado, e assim poderia acontecer discursões públicas de qualidade para ocasionar uma participação rápida, ágil, civil, sem limite de tempo e espaço, de forma que o participante fique mais cômodo, tenha mais conforto e uma maior conveniência (GOMES, 2005). E o último ponto, o sistema político tem que incentivar o cidadão a continuar participando, discutindo e votando. 
No Brasil, vários autores (SAMPAIO, 2009) indicam que os sites do governo são focados na entrega de serviços ao cidadão, mas ainda não mostram ambientes informativos densos, muito menos é efetivada uma ferramenta de participação popular. Com isso, é perceptível que os sites do governo estão distantes da governança eletrônica, isto é, ainda estão em um modelo de governo eletrônico primário, incapaz de reestruturar as relações dos governantes e a sociedade civil.

Entretanto, há exemplo de sistemas bem desenvolvidos, como os movimentos sociais bem estruturados e demandado pela maior parte da população de Porto Alegre no ano de 1989, resultaram na criação do Orçamento Participativo na cidade. A Constituição de 1988 facilitava uma participação da população nas decisões do município, sendo no mandato de governante ligado ao Partido dos Trabalhadores (PT), foi que elaborou esta abertura da prefeitura (AVRITZER, 2005). De fato, o Orçamento Participativo se firmou na cidade e teve destaque em meio a população, ao meio político e até mesmo na academia, pois foi reconhecido como uma governança popular por promover uma renovação instituição e uma força efetiva para interferir no rumo das políticas públicas Sampaio (2009, apud, AVRITZER, 2005, 2006; NAVARRO, 2005; FUNG; WRIGHT, 2000).

Todavia, por não se enquadrar nos tipos de obras realizáveis pelo OP ou que não estivessem no padrão solicitado pela prefeitura, mais da metade não chegaram a ser discutidas no fórum dos delegados (PORRAS, 2004). Assim, boa parte das escolhas feitas pela internet era desenvolvida a seus autores para uma revisão e bastante delas não eram submetidas novamente. Por isso, Pessi (2003) e Porras (2004), afirmam que isto foi um fator substancial para o declínio das demandas enviadas.

Avritzer (2005) afirma que existe uma potente ligação dos órgãos no Orçamento Participativo Presencial e uma maior eficiência administrativa, pois há necessidade de que exista essa ligação, devido ao conhecimento e responsabilidade de operacionalizar cada serviço. Além disso, o OP acaba disponibilizando um acompanhamento civil, gerando assim uma menor chance de corrupção e/ou gastos desnecessários pelos órgãos estatais.

Nessa perspectiva, portanto, é impossível deixar de insistir na sociedade civil, e na possibilidade desta de acessar de forma abrangente, por meios eletrônicos, o governo, e interferir positivamente na agenda pública, resgatando por uma perspectiva republicana a esfera estatal, como relata Ruediger (2002).

A questão dos problemas da democratização e reestruturação do Estado, passa pela superação da dicotomia entre membros de um governo Estamental e sociedade civil, e pode ser alcançado no campo da utilização das novas mídias interativas, a partir de uma abertura planejada do projeto para a inclusão de percepções diversas, que organizadas, ampliem a responsabilidade dos sistemas e, mesmo, alterem sua relação hierárquica, promovendo mecanismos de participação nos processos de formulação e feedback da administração, transformando, notadamente, os mecanismos de serviços ad hoc de governo eletrônico em mecanismos políticos e sistêmicos de governança (RUEDIGER, 2002).

Frey e Rezende (2005) apesar de afirmarem que há necessidade de um Estado engajado, disposto a permitir contribuições da população local para influenciar a tomada de decisões, afirmam a necessidade de uma vontade política da população em confiar no investimento do governo e assim empregar as novas tecnologias para atingir seus objetivos particulares. 
Estudos acerca de programas participativos, em especial OP's (AVRITZER, 2005, 2006), apontam existir uma relação direta dos índices de participação popular com a efetividade dos processos em uma espécie de efeito demonstração. Pode-se então resumir a governança eletrônica desejável, transformadora do Estado em três pontos básicos: primeiramente;

a) é preciso vontade política. Um Estado engajado disposto a desafiar as hierarquias tradicionais de poder e assim permitir contribuições da população local para influenciar tomada de decisões. Para tanto, a internet apresenta-se como ferramenta interessante para auxiliar esta renovação do Estado. Neste ponto, é importante a oferta de ferramentas online;

b) que permitam a procura de informações políticas qualificadas sobre o governo, que possibilitem monitoramento das obras e realizações do Estado, que propiciem discussões públicas de qualidade, capazes de facilitar a definição das políticas públicas necessárias aos cidadãos, e principalmente que possibilitem uma participação civil ágil, viável, sem limites de tempo e espaço, oferecendo comodidade, conforto, conveniência ao participante (GOMES, 2005). Finalmente, as ferramentas criadas para estes fins devem ter efeitos reais;

c) no sistema político, que sejam percebidos pelo cidadão, incentivando-o a continuar discutindo, votando e participando. No caso brasileiro, vários autores (RIBEIRO FILHO; CARNEIRO, 2008; FREY, 2000; GOMES, 2005a, RUEDIGER, 2002) apontam o predomínio de sites governamentais focados na entrega de serviços públicos aos cidadãos, que ainda não exibem nem ambientes informativos densos, nem efetivas ferramentas de participação popular.

Há linhas de pensamento que se mantêm em um conceito mais aberto como o de Rezende e Frey (2005, p. 107): “A governança eletrônica ou e-governança (e-gov) pode ser entendida como a aplicação dos recursos da TI na gestão pública e política das organizações desse tipo". Prado e Loureiro (2006, p. 108), por exemplo, utilizam o conceito definido pela ONU e entendem o e-gov: "como o conjunto de plataformas tecnológicas de comunicação, informação e aplicações em usos pelo setor público".

Cunha (2005) baseia sua pesquisa na conceituação da UNESCO, que divide a e-governança, entendida como o uso das TIC's para atingir uma boa governança, em três áreas: e-administração, e-serviços e e-democracia. A UNESCO define a e-administração como "o uso dos meios eletrônicos para a administração pública. O e-serviços, como a prestação de serviços eletrônicos ao cidadão e às empresas. $O$ terceiro conceito, e-democracia, ou democracia eletrônica, seria o uso dos meios eletrônicos no suporte à prática democrática" (CUNHA, 2005, p. 2). Já para Borges e Silva (2006), a governança eletrônica é uma dimensão do governo eletrônico que "incorpora as TIC's para dar suporte aos gestores públicos de diferentes escalões na tomada de decisões, na elaboração e implementação de políticas públicas, entre outros, visando dinamizar a ação governamental" (BORGES, SILVA, 2006, p. 133). Apesar da indefinição conceitual, diversas experiências vêm sendo realizadas por governos no mundo inteiro, nos mais diversos níveis, nacional e subnacional, com os mais diversos objetivos, porém com um foco em comum: a utilização das TIC's pela Administração Pública Best et al., (2010, apud, PEEL, 2009; RIBEIRO, 2008; FREY, 2005; REZENDE, FREY, 2005; VAZ, 2003). 
O conceito de governança eletrônica, que é o adotado nesta pesquisa, proposto por Vaz (2005, p. 14) entende que: "Só é possível falar de governança eletrônica como o uso das TIC's aplicado a relação entre governo e sociedade organizada a partir do entendimento das possibilidades tecnológicas ofertado pelos recursos do chamado governo eletrônico". Apesar de não haver um consenso sobre o conceito de governança, para fins deste estudo, experiências em que os governos promovam iniciativas voltadas para o cidadão e a relação destes com o governo, através das TIC's, serão consideradas experiências de governança eletrônica.

Para Vaz (2005), as TIC's podem servir para melhorar a qualidade das relações entre governos e cidadãos pelo seu potencial de promotoras de direitos, como por exemplo o direito à informação, ao serviço público, ao seu próprio tempo, de ser ouvido pelo governo, ao controle social sobre o governo e à participação na gestão pública. Os últimos três direitos mencionados estão relacionados ao exercício dos direitos coletivos, e é neste ponto que a governança eletrônica tem potencial para promover a ampliação dos direitos do cidadão na gestão pública, bem como de transformar os processos de deliberação, monitoramento e avaliação do OP, ampliando o direito à participação na gestão pública e democratizando o acesso às ferramentas de informação e comunicação, garantindo um maior número de participantes nestes processos democráticos participativos.

Inicialmente o site do Orçamento Participativo (OP) de Porto Alegre (1995) era simples, o mesmo apenas reproduzia informações contidas em outros meios de comunicação, tais como: TV, rádio, folhetos da própria prefeitura, jornais de telecomunicações e etc (PESSI, 2003). Já no ano de 2000, foi disponibilizada uma ferramenta para prestar contas, o que concedeu ao cidadão a possibilidade de acompanhar desde a contratação até a execução das obras. Em 2001, foi iniciado o processo que pode ser denominado como Orçamento Participativo eletrônico, já que foi inserida outra ferramenta que permita a sugestão de obras pela internet. Isso resulta numa aproximação no projeto de governança eletrônica. Então, através do endereço eletrônico da prefeitura de Porto Alegre, era possível enviar as mesmas solicitações que poderiam ser enviadas pelo OP presencial. As demandas que eram passíveis de alterações, eram analisadas por alguns técnicos da prefeitura e caso precisasse de ajustes, os mesmos enviam a resposta ao cidadão. Caso acontece de as deliberações serem aceitas, elas seriam incorporadas nos Fórum dos delegados do OP presencial. E através da internet, a população constantemente era contatada para receber informações do processo de forma geral. De acordo com Sampaio (2009):

Todavia, grande parte das demandas digitais não se enquadrava no tipo de obras realizadas pelo OP ou ainda no padrão exigido pela prefeitura, assim, mais de $70 \%$ não chegou às assembleias regionais. Desta forma, grande parte das indicações realizadas pela internet era devolvida ao usuário para revisão e muitas acabavam não sendo enviadas novamente. Para Pessi (2003) e Porras (2004), este foi um fator fundamental para a queda no número de envio de demandas. O número de sugestões foi de 600 em 2001, caiu para 193 em 2002 e depois para 100 em 2003. (SAMPAIO, 2009, p. 131).

Desta forma, o objetivo era reforçar o processo presencial ao invés de substitui-lo (PESSI, 2003). Caso a sugestão do cidadão fosse aceita, o mesmo deveria comparecer no fórum de delegados para defender sua proposta, ou resultaria de ter mínimas chances de ir adiante. 
A partir disso, o tópico a seguir comtempla os limites e possibilidades de uso das TIC's no $\mathrm{OP}$, enfatizando, assim como, os direitos a limitação ou ampliação das tecnologias de informação no ambiente do Orçamento Participativo.

\subsection{Limites e possibilidades de uso das TIC'S no OP}

De acordo com Peixoto (2009) a utilização do sistema virtual como apoio ao Orçamento Participativo permitiu a substituição das reuniões presenciais, o que significa uma intermediação que não exige contato direto entre os munícipes e diminui custos da participação. Ademais, no OP presencial todas as etapas são definidas pelos cidadãos em conjunto a prefeitura, ou seja, desde a escolha das obras para a votação até o monitoramento.

No caso, por exemplo, de Belo Horizonte, a Prefeitura propôs os projetos que seriam votados pelos cidadãos na deliberação online. Portanto, pode-se questionar se eles continuarão com este poder de determinação das obras a serem votadas no próximo OP Digital, ou será que a sociedade civil clamará por este direito de indicar obras como já ocorre no OP Presencial, em que todas as decisões desde as propostas até as escolhas das obras e monitoramento são definidas pelos cidadãos? Um dos limites do OP Digital é a sua real capacidade de promover o debate na participação. Apesar de abrir espaços para a participação online como fóruns e chats, o processo do OP Digital de Belo Horizonte não permite a escolha das obras e nem há um espaço de monitoramento formal pelos cidadãos.

Podem ser determinados alguns fatores, além dos tecnológicos, para que o uso da internet no OP realmente se caracterize como promotor da participação dos cidadãos:

a) Os cidadãos perceberem que fazem a diferença no processo decisório, ou seja, eles veem os resultados da sua participação (PEIXOTO, 2009; SAMPAIO, 2009; PESSI, 2003);

b) Vontade política, ou seja, os governos têm que se engajar no projeto para manter o uso da internet no OP e incentivar a população a participar (PEIXOTO, 2009; SAMPAIO, 2009);

c) Comunicação da iniciativa, ou seja, salientar a importância da iniciativa através da disponibilização de informações sobre o processo e incentivo a participação (PEIXOTO, 2009);

d) Existência de um relacionamento bidirecional entre governos e cidadãos, ou seja, garantir que ambos participem do processo de OP (PESSI, 2003; SAMPAIO, 2009).

Em consonância com os fatores tecnológicos, a maior limitação para a participação no OP virtual é a exclusão digital. Tais limitações são aceitas e consideradas pelos municípios, pois todos aqueles que realizaram experiências de votação ou coleta de propostas através da internet também disponibilizaram diversos pontos de acesso públicos e com monitores para auxiliar no uso dos computadores durante todo o processo.

Sobre as restrições e riscos da utilização da internet no OP, foi realizada, por Sampaio (2009) uma pesquisa por meio de questionário no evento "VIII Repensando o Orçamento Participativo", ação conjunta entre o Instituto Pólis e o Fórum Paulista de Orçamento Participativo. A pesquisa contou com a participação de 42 pessoas, o que corresponde a $63 \%$ dos participantes do evento, 
que responderam o questionário sobre o uso da internet no OP. A maioria dos presentes (85\%), que se dividia entre pessoas do governo ou da sociedade civil, participava ou já tinha participado de experiências de OP.

Os principais benefícios citados estão associados às possibilidades de maior acesso à informação, comunicação e participação proporcionado pelas TICs. Dito isso, as principais limitações citadas estavam relacionadas à exclusão digital, à perda de participação e à falta de informação, conhecimento e capacitação devido ao digital gap (sistema de informação descontínuo) existente no país, o que acaba por alimentar um ciclo vicioso de exclusão social e política em um processo participativo de caráter democrático.

O uso da internet para o OP em todas as etapas do processo foi rechaçado pela maioria dos participantes desta pesquisa. A internet é aceita como um meio complementar ao OP, principalmente no que tange à consulta de propostas e monitoramento. Seria importante aprofundar essa discussão para melhor compreender as inseguranças, tanto do poder público quanto dos cidadãos, acerca do uso da internet em todas as etapas do OP.

Vale também levar em consideração que a tomada de decisão pela internet, em certo sentido, acaba se aproximando mais da democracia direta do que de fato aprofunda a democracia participativa.

Uma das reflexões possíveis é a falta de diálogo e discussão acerca das propostas apresentadas ao OP por meio digital, uma vez que a impessoalidade da discussão virtual acaba por diminuir o caráter de democracia deliberativa do OP tradicional. A partir disso, a seguir contemplase uma discussão sobre Orçamento Participativo, por meio dos seus pontos positivos e negativos, compreendendo sua função nas políticas públicas.

\subsection{Orçamento participativo virtual}

O direito à participação na gestão pública se refere à participação e interação do cidadão com as decisões da administração pública. Dentro do direito à participação na gestão pública, de acordo com a tipologia apresentada por Vaz (2003) para explicar como os sítios governamentais podem aumentar as possibilidades de exercício deste direito, estão às experiências de Orçamento Participativo Digital (OP Digital), ou seja, a utilização das TIC's em qualquer etapa do OP Best et al., (2010, apud, LOGOLINK, 2010).

Nos últimos anos, a internet foi mais amplamente utilizada no Brasil para reforçar e/ ou complementar os programas de OP. Uma das justificativas para este movimento é que, apesar do digital gap existente, o uso da internet é considerado como uma oportunidade para a ampliação da participação no OP no âmbito local, envolvendo cidadãos que tradicionalmente não participariam dessa iniciativa (SAMPAIO, 2009; PESSI, 2003; PEIXOTO, 2009).

As experiências brasileiras aqui estudadas utilizam a internet em diferentes etapas do OP: na primeira etapa de envio de propostas, votação e no fechamento do ciclo, através de mecanismos de prestação de contas.

O envio de propostas do OP através da internet permite a coleta de demandas para a votação do OP. Esse é o exemplo do Município de Ipatinga em Minas Gerais. As experiências de votação online do OP se referem à realização de votação dos empreendimentos do Orçamento 
Participativo do município através da internet como já ocorre em Belo Horizonte como por exemplo; e Recife nos estados de Minas Gerais e Pernambuco, respectivamente (LOGOLINK, 2010). O uso da internet para a prestação de contas do OP fecha o ciclo deste processo e é encontrado em diversos municípios brasileiros, contudo, para fins desse artigo, o exemplo do Município de Porto Alegre será usado.

Enquanto observa-se que em nenhum caso utiliza a internet em todas as etapas do Orçamento Participativo (OP), observa-se ainda que, se somados, o uso da internet nas diferentes etapas, nos casos estudados, significa que é possível desenvolver um Orçamento Participativo (OP) $100 \%$ digital, ou seja, significa que seria tecnologicamente possível utilizar a internet em todas as etapas do OP.

Ainda de acordo com Vaz (2002) faz-se importante observar que não existe uma metodologia imutável para a implementação do OP e que, em cada versão, o OP assume características apropriadas ao seu local de realização, assim como responde aos interesses dos stakeholders que estão à frente do processo.

Considera ainda que ao utilizarem as TIC's na realização do OP Digital em suas localidades, os munícipios vão além das exigências mínimas de participação do $O P$, buscando maneiras inovadoras, complementares ao modelo tradicional de ampliar a participação dos cidadãos ao longo das diferentes etapas que compõem o OP.

O surgimento de experiências como essas, que fazem uso da internet para promover uma maior interação entre governos e seus cidadãos, se tornam mais presentes uma vez que se vive numa era de grande desenvolvimento das TIC's, e consequente barateamento e difusão dessas tecnologias.

De acordo com Vaz (2002) o argumento central é que o uso da internet permite que as experiências de Orçamento Participativo (OP) amplie a participação cidadã nos processos deliberativos, ou seja, garante que milhares de cidadãos, que antes não participariam do processo, deliberem sobre a melhor alocação dos investimentos públicos em seus municípios.

Acrescenta ainda que a possibilidade criada pela deliberação virtual gera uma série de questionamentos e inseguranças sobre o caráter de fortalecimento democrático do OP digital. O $\mathrm{OP}$, que é tradicionalmente visto como uma ferramenta de inclusão e participação, é um exercício de cidadania onde, por meio do debate e da deliberação sobre um percentual do orçamento municipal, se exerce a democracia participativa.

\section{METODOLOGIA}

Nesse enquadramento, o estudo pondera estruturalmente a pesquisa, tornando possível melhor compreende-la. Por meio da pergunta problema, vislumbrou-se entender como o Orçamento Participativo Virtual pode servir a gestão municipal da cidade do Natal/RN como um mecanismo de governança eletrônica. A partir disso, constituiu-se uma pesquisa de caráter descritivo, por realização de um estudo através de análise, registros e interpretação de um instrumento, com a finalidade de observar o sistema do Orçamento Participativo Virtual (OPV). Além disso, verifica-se um estudo de linha exploratória, por meio da qual guia-se pela problemática em questão. Em conformidade com Yin (2015) o estudo exploratório remete a uma resposta 
rápida, mas excessivamente limitada - justificando a utilização das duas classificações a presente pesquisa - descritiva e exploratória - para que seja alcançado os resultados.

O presente estudo remete a um estudo de caso único, com direcionamento a utilização do OP como um mecanismo de governança eletrônica. Para tanto, utiliza-se um uma abordagem qualitativa, priorizando a busca por dados primários, que no caso do estudo em questão adotouse como sujeito da pesquisa a diretora do Departamento de Planejamento e Participação popular (DPP) da Secretária Municipal de Planejamento da Prefeitura do Natal. Em consonância com Yin (2005, p. 32) por meio dessa linha "o estudo de caso é uma investigação empírica que investiga um fenômeno contemporâneo dentro de seu contexto da vida real".

Na pesquisa, a coleta de dados, foi desenvolvida via entrevista semiestruturada, presente no apêndice, com base no problema de como o Orçamento Participativo Virtual pode servir a gestão municipal da cidade do Natal/RN como um mecanismo de governança eletrônica. Com um instrumento de coleta construído a partir do acervo literário, tornou-se possível extrair informativos a respeito da interação popular diante das ações governamentais, gerando também maior transparência. Sendo possível a construção do instrumento de coleta de dados aplicado presencialmente com a diretora do Departamento de Planejamento e Participação Popular, a partir de uma visita in loco, gerando as respostas do estudo.

Por meio da construção de um instrumento de coleta de dados - questionário -, a partir da revisão literária, tornou-se possível aplica-lo com direcionamento ao Departamento de Planejamento e Participação popular, de maneira que a captação dos dados primários supriu a necessidade de esclarecimento ao estudo, para melhor compreensão da problemática. Soma-se a isso, o alinhamento de pesquisa, com contemplação principal na governança eletrônica, Orçamento Participativo Virtual e integração

\section{ANÁLISE DE RESULTADOS}

Com referência ao acervo teórico, tornou-se possível a construção dos resultados. A partir da pergunta problema - como o Orçamento Participativo Virtual pode servir a gestão municipal da cidade do Natal/RN como um mecanismo de governança eletrônica, constituiu-se a análise abaixo.

\subsection{Secretaria Municipal de Planejamento, Fazenda e Tecnologia da Informação (SEMPLA).}

Em análise ao Orçamento Participativo, com direcionamento a SEMPLA, cita-se como competência da Secretaria: promover o planejamento global do Município, em articulação e cooperação com os níveis federal e estadual de governos; gerir o sistema de informações para o planejamento estratégico da Grande Natal, conduzindo as articulações para a implementação do Plano de Desenvolvimento Integrado de Natal; além de integrar ações com vistas ao desenvolvimento da Região Metropolitana; formular estratégias, normas e padrões de operacionalização, avaliação e controle de ações governamentais, no âmbito do Município; coordenar e articular projetos multissetoriais; coordenar, em articulação com o Gabinete do Prefeito, os entendimentos do Município com entidades municipais, estaduais, federais, internacionais e outras para obtenção de financiamentos ou recursos a fundo perdida para o desenvolvimento de programas municipais. 
Soma-se a isso a competência em coordenar o sistema de informações governamentais, em especial os relatórios de atividades dos órgãos municipais; prestar apoio técnico e administrativo ao COMCIT; prestar apoio técnico, em matéria de planejamento e administração, ao Conselho Municipal de Saneamento Básico - COMSAB, conjuntamente com a Agência Reguladora de Serviços de Saneamento Básico do Município de Natal - ARSBAN; planejar, coordenar, supervisionar e orientar as atividades, políticas e diretrizes da tecnologia da informação no âmbito da Administração Municipal Direta e Indireta.

Convém, ainda, mencionar dentre as competências a de promover a realização de estudos e pesquisas sobre a realidade socioeconômica do Município de Natal e da Região Metropolitana; elaborar, em articulação com os órgãos e entidades públicas da Administração Municipal, a proposta orçamentária do Município; elaborar o projeto de Lei Orçamentária Anual do Município; estabelecer o programa de execução orçamentária, acompanhar e avaliar a sua efetivação; estabelecer a programação financeira de desembolso para os programas e atividades da Administração Municipal; administrar os recursos financeiros do Município; orientar e supervisionar tecnicamente as atividades de execução orçamentária e financeira das Secretarias e Órgãos e Entidades Públicas da Administração Direta e Indireta; expedir atos normativos concernentes à elaboração orçamentária, à execução e à administração das dotações e dos recursos municipais.

Por fim, a secretaria ainda estabelece normas gerais para a elaboração da Lei de Diretrizes Orçamentárias do Município; elaborar, consolidar e acompanhar o Plano Plurianual do Município; estabelecer e promover as medidas assecuratórias do equilíbrio orçamentário e financeiro do Município; realizar, com exclusividade, a contabilidade geral dos atos e dos recursos financeiros do Município; proceder, no âmbito do seu Órgão, à gestão e ao controle financeiro dos recursos orçamentários previstos na sua Unidade, bem como à gestão de pessoas e recursos materiais existentes, em consonância com as diretrizes e regulamentos emanados do Chefe do Poder Executivo; exercer outras atividades correlatas.

\subsection{Departamento De Planejamento E Participação Popular}

De acordo com a diretora do Departamento de Planejamento e Participação Popular, da Secretaria Municipal de Planejamento (SEMPLA), a priori, determinou-se como se dá participação da população na ferramenta virtual do Orçamento Participativo, e atribuiu-se a sua criação, por meio da planilha do Google Docs que é uma ferramenta disponibilizada pelo Google. O acesso dáse por meio de um banner exposto no site da Prefeitura do Natal que ao ser clicado redireciona para a planilha a qual contém o formulário de credenciamento que, ao ser preenchido envia as informações para o banco de dados onde mantem-se armazenado as informações prestadas pelo cidadão.

Acrescenta-se a isso, a divulgação da ferramenta, que ocorreu, especificamente, durante as plenárias presenciais com a população, e ainda nos eventos promovidos pela sociedade organizada.

Conforme relatado pela diretora do departamento, o estímulo para elaboração do Orçamento Participativo Virtual deu-se a partir da necessidade de ampliação do público, assim como, pela diversificação do público envolvido no Orçamento Participativo Virtual, pois na modalidade do Orçamento Participativo a faixa etária adulta se faz presente. 
Soma-se a isso, a maior vantagem do Orçamento Participativo Virtual, em ampliar o alcance de forma mais ampla que o Orçamento Participativo, pois através da divulgação por meio das redes sociais o alcance é mais rápido e de maior abrangência comparado a divulgação em cada plenária realizada. Além disso, incorpora um novo público, os jovens. Esse público por possuir uma relação de entretenimento e discursões sociais, se faz protagonista, sendo os mais atingidos, já que grande parte da divulgação em ambiente externo ocorre por meio das redes sociais - além de ocorrerem nas plenárias e eventos da prefeitura do Natal. Em conformidade a isso, a Diretora do departamento apresentou dados que comprovam essa afirmativa.

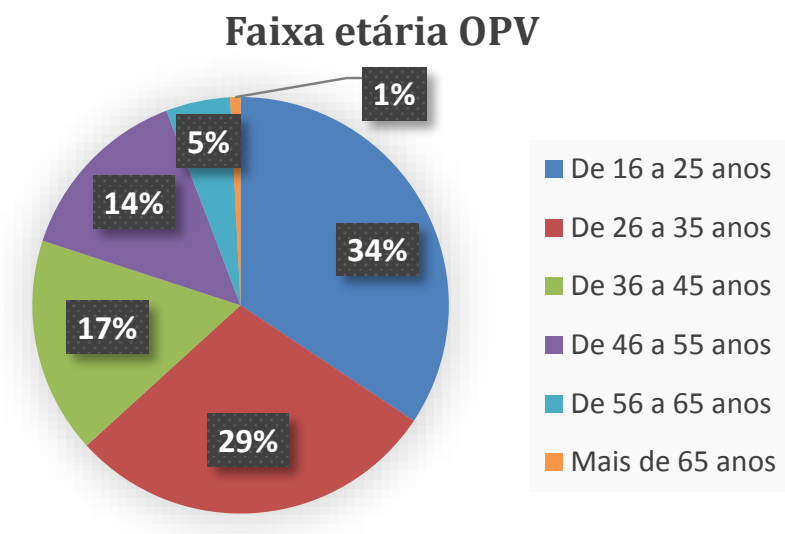

Gráfico 01 - Faixa etária de participação no OPV 2015 Fonte: Adaptação do banco de dados do DPP, 2015.

Diante do exposto acima no gráfico 01 o OPV teve a participação total de 876 munícipes, sendo os 34\% representantes da faixa etária de 16 a 25 anos, com 301 pessoas; 29\% correspondente à faixa etária de 26 a 35 anos, com 253 pessoas; $17 \%$ referente dos munícipes de faixa etária de 36 a 45 anos, com 147 pessoas; 14\% da faixa etária de 45 a 55 anos, com 124 pessoas; $5 \%$ referente ao pessoal da faixa etária de 56 a 65 anos, com 44 pessoas e por fim, o público com mais de 65 anos que representa menos de $1 \%$ dos participativos,

No que remete aos recursos, a população obtém controle a partir das demandas escolhidas por meio do acompanhamento do plano de investimento do OP enviado para os delegados e delegadas do OP que, por sua vez, passam a exercer o controle social junto as secretarias municipais, relata a diretora. Convém, ainda, mencionar deficiências do OP Virtual relatadas pela diretora;

\footnotetext{
O que falta para o Orçamento Participativo ser uma ferramenta útil é a divulgação, atualmente fraca, atingindo apenas uma pequena parcela da população. Ainda há também a necessidade de compreender os processos, pela população; e o espaço para deliberações sobre as temáticas.
}

Diante do mencionado acima, percebe-se que o Orçamento Participativo não tem resultados expressivos porque além da divulgação ser fraca, o processo informativo não é trabalhado com a população. Elaborar uma divulgação em massa com plenárias regionais explicativas além de ajudar na divulgação do OP já que existem muitos munícipes que desconhecem a ferramenta, ajudaria a aqueles que conhecem sanarem todas as suas dúvidas em referência a proposta. 
Ainda em consonância com a diretora, atualmente o maior problema do Orçamento Participativo Virtual (OPV) refere-se a falta de divulgação da existência dessa ferramenta, preservando um desconhecimento da população frente aos seus direitos. Além disso, há uma impossibilidade de se deliberar sobre a ações e serviços em conformidade com as temáticas priorizadas, pois a população credenciada no OPV preenche uma ferramenta com alternativas a serem assinaladas, impedindo o munícipe de opinar e direcionar sua prioridade em referida temática, como apresentado na figura 01 abaixo;

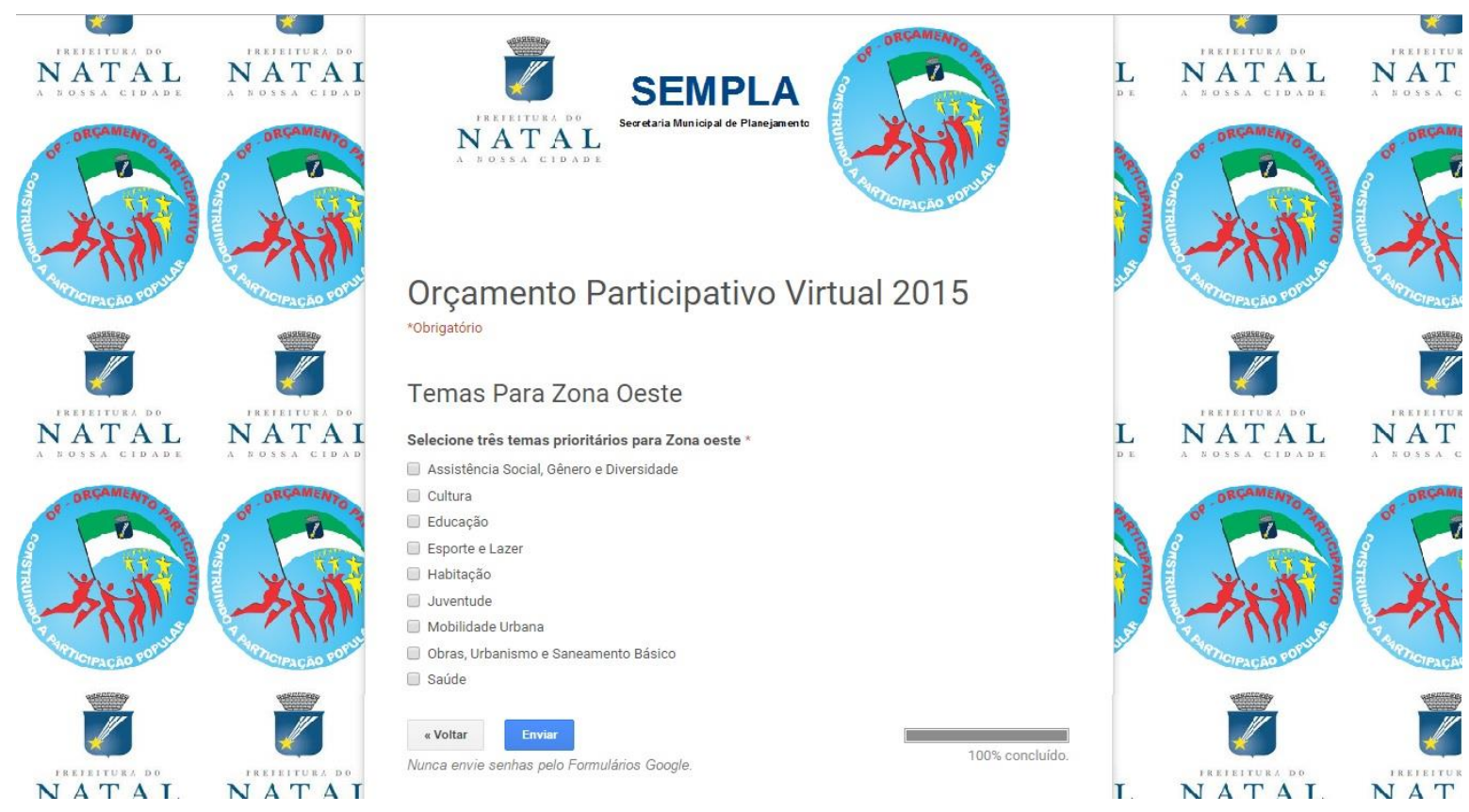

Figura 01 - Orçamento Participativo Virtual, 2015. Fonte: SEMPLA, 2015.

A diretora do departamento acrescenta ainda a ausência de alguma ferramenta que a população possa acompanhar as ações, relatando;

\footnotetext{
Atualmente o único ponto de apoio está no Whatsapp, onde ocorrem a comunicação com os delegados (as) do OP e o e-mail, por meio onde são repassados os planos de investimentos contendo ações e serviços deliberados pela população para a cidade com suas respectivas situações junto às secretarias responsáveis pela execução.
}

A partir disso, sem meios de comunicação que alcance um maior número populacional, limita-se o alcance a todos devido à disponibilidade de ferramentas de forma desproporcional. Assim, o processo não consegue oferecer uma total transparência, fazendo com que o não tenha uma forma mais eficiente, impossibilitando assim uma maior confiança e credibilidade frente aos cidadãos.

O Orçamento Participativo, do ponto de vista que remete a aproximação da população à gestão, fundamenta em atividades integradas e articuladas entre a população e a gestão permitindo uma aproximação da população que, por sua vez toma conhecimento da dinâmica de cada secretaria e dos desafios por elas enfrentados, colocando-se como corresponsáveis pela gestão, como relatado pela diretora do departamento. 
Acrescenta-se ainda, que o maior problema em dirigir o Orçamento Participativo da cidade, remete a falta de cultura da participação agregada, desvalorizando o processo. Isso pode ser justificado pela falta de conhecimento da população em relação aos recursos existentes para aplicação de suas necessidades. Por meio disso, dá-se ao baixo número de credenciamentos dos munícipes levando em consideração o número de habitantes da cidade.

No sistema da integração da população, os mesmos podem participar através do espaço virtual para credenciamento da população, que preenche um formulário de cadastro contendo informações sócias econômicas apenas para ter como base uma divisão mais apropriada da situação a partir da região de cada munícipe e da escolha de áreas temáticas. O espaço virtual foi estruturado a partir de uma ferramenta do Google Docs que pode ser acessado através de um banner no portal informativo da Prefeitura do Natal.

Em contraponto, determina por ponto fraco a impossibilidade de promover uma discussão com esse público, tendo em visto a inexistência de um aplicativo, que venha a estimular a participação populacional em tempo real, e que venha a tornar o evento mais ágil, atingindo um maior contingente de pessoas, sem a necessidade de fazê-las deslocar-se de seu ambiente íntimo.

\section{CONSIDERAÇÕES FINAIS}

O presente estudo teve como objetivo geral a ambição de analisar o Orçamento Participativo Virtual como um mecanismo de governança eletrônica da gestão municipal da cidade do Natal/RN, buscando atribuir por benefício, maior interação entre população e gestão. Além disso, na construção dos objetivos específicos buscou-se analisar as contribuições dos munícipes em sua inserção do Orçamento Participativo Virtual; levantar o status de execução das ações e serviços deliberados pela população a partir do Orçamento Participativo; evidenciar as características fortes e fracas do processo de Orçamento Participativo Virtual no que diz respeito à promoção de valores democráticos; e avaliar o site do Orçamento Participativo Virtual do município do Natal/RN no que diz respeito ao ambiente informativo e às ferramentas participativas.

No primeiro objetivo, de analisar as contribuições dos munícipes em sua inserção do Orçamento Participativo Virtual, tornou-se possível por meio do estudo, visualizar a minimização de custos, já que com a ampliação da participação popular, os investimentos ocorrem de acordo com as necessidades de determinada região, gerando assim uma redução em investimentos que poderiam não suprir as necessidades da população.

Referente ao próximo objetivo de levantar o status de execução das ações e serviços deliberados pela população a partir do Orçamento Participativo, foi compreendido através do presente estudo que os delegados e delegadas do OP buscam informações sobre as obras deliberadas, entretanto, não existe nenhum canal informativo para divulgação do status da obra depois que as informações são coletadas, a não ser que cada munícipe procure o Departamento de Planejamento e Participação Popular.

Em relação ao foco de evidenciar as características fortes e fracas do processo de Orçamento Participativo Virtual, no que diz respeito à promoção de valores democráticos pode-se ser citado como fator positivo a representação direta da sociedade exercendo seu direito, além de demonstrar uma responsabilidade cívica naquilo que representa e vota para ser deliberado. Como 
ponto negativo pode ser evidenciado o fato da exclusão digital, pois o OPV só é válido para aqueles que tem acesso à Internet.

Por fim, o último objetivo de avaliar o site do Orçamento Participativo Virtual do município do Natal/RN, no que diz respeito ao ambiente informativo e às ferramentas participativas, traz uma forte deficiência em seu âmbito de informações, já que atualmente o OPV conta apenas com uma ferramenta, a qual remete a um formulário que solicita informações para credenciamento do munícipe e para uma caracterização socioeconômica da região administrativa que o munícipe habita.

A partir disso, recomenda-se um maior investimento na divulgação do Orçamento Participativo Virtual para que exista um maior número de credenciamento, aumentando assim, a participação da população no OPV. Além disso, adiciona-se o fato de que há necessidade de um portal interativo para que se tenha uma maior captação da opinião da sociedade quanto as obras e serviços que devem ser realizadas, pois nos dias atuais o OPV conta com temáticas prioritárias indicativas impossibilitando que a população opine na aplicação dos recursos. Também ainda no portal deve conter um espaço informativo para que exista informações dos status das obras para aqueles munícipes que não tem o referido contato com o delegado representante de sua região.

Além dos benefícios tratados acima, a pesquisa identificou a minimização dos custos atingindo maior número de indivíduos, pela facilidade de acesso, já que nesse ambiente demandase menor tempo desprendido com deslocamentos ou espera em reuniões, gerando por consequência o aumento no número de retornos, atribuindo à população um novo canal de participação. Podendo opinar e/ou informar sobre as possíveis demandas e necessidades de cada região.

Percebe-se, portanto, que os resultados aqui encontrados para o OPV, quais sejam: o aumento dos munícipes participantes, sendo estes com faixa etária mais jovem, assim como a minimização de custos, está em consonância com a literatura aqui apresentada (FREY, 2000; PEIXOTO, 2009; SAMPAIO, 2009; PESSI, 2003).

Acrescenta-se ainda como contribuição, que exista uma maior interação e planejamento por parte das secretarias responsáveis por cada temática. Pois desta forma, poderia ser extinto o plano de investimento, uma vez que, seria introduzido na LOA pela própria secretaria a verba destinada para execução das temáticas deliberadas pela população. Quando a secretaria fosse realizar o planejamento orçamentário para a LOA iria inserir a verba necessária para a realização da sua obra. Assim, quando a prefeitura enviasse a Lei Orçamentária Anual para a Câmara Municipal dos Vereadores, estaria sendo planejada as ações para o ano seguinte, levando a uma maior agilidade na execução das temáticas, tendo em vista que a execução de cada obra seria feita no respectivo ano de sua eleição.

Cabe ressaltar ainda, a necessidade de estudos complementares para compreender como gerar uma ampliação nos estudos de acesso a tecnologias de informação a todos, para que ocorra uma expansão da interação com maior participação.

Estudos esses que compreendam melhor essa relação entre o OP Digital e o OP Presencial. Outra questão pertinente para estudos futuros diz respeito às restrições e dificuldades para a utilização das TIC's em processo participativo. Assim, além dos fatores tecnológicos, em que se 
inclui a exclusão digital, diversos autores apresentam alguns fatores que possibilitariam o aumento da participação nos processos de OP através da internet.

Por fim, com o fomento em compreender como o Orçamento Participativo Virtual pode servir a gestão municipal da cidade do Natal/RN como um mecanismo de governança eletrônica, tornou-se possível a partir da captação dos dados primários, compreender, que o Orçamento Participativo Virtual pode servir a gestão com a diminuição de plenárias e eventos, minimizando assim custos, o que permite menor atribuição de tempo disponibilizado ao processo. Além disso, processar ainda maior participação do público jovem, ampliando o público, além de maior controle sob as demandas, aplicando certamente os recursos.

\section{REFERÊNCIAS}

1. ABREU, J. C. A. de. Democracia, Hegemonia e Internet: um Estudo de Caso sobre o Orçamento Participativo Digital. (Dissertação de Mestrado) - Universidade Federal da Bahia, 2009.

2. ALMEIDA, L. de S. B. A gestão participativa em administrações municipais: as experiências de Natal e Maceió. 2006. Tese (Doutorado em Ciências Sociais) - Centro de Ciências Humanas, Letras e Artes, Universidade Federal do Rio Grande do Norte, 2006.

3. Modelos de deliberação democrática: uma análise do orçamento participativo no Brasil. In: Boaventura de Sousa Santos [Org.]. Democratizar a Democracia: Os caminhos da Democracia Participativa. Rio de Janeiro: Civilização Brasileira, 2005.

4. AVRITZER, L. New public spheres in Brazil: local democracy and deliberative politics. International Journal of Urban and Regional Research, v. 30, p. 623-637, 2006.

5. BENTIVEGNA, S. Rethinking politics in the world of ICTs. European Journal of Communication, n. 21, p. 331-343, 2006.

6. BORGES, J.; SILVA, H. P. da. Democracia eletrônica e competência informacional. Informação e Sociedade, v. 16, n.1, p. 129-137, jan./jun. 2006.

7. CHADWICK, A. Bringing e-democracy back: why it matters for future research on egovernance. Social Science Computer Review, n. 21, p. 443-455, 2003.

8. CUNHA, M. A. Meios eletrônicos e transparência: a interação do vereador brasileiro com o cidadão e o poder executivo. In: CONGRESO INTERNACIONAL DEL CLAD SOBRE LA REFORMA DEL ESTADO Y DE LA ADMINISTRACIÓN PÚBLICA, X, Santiago, Chile, 18-21 Oct. 2005.

9. DAHLREN, P. The internet, Public Spheres, and Political Communication: Dispersion and Deliberation. Political Communication, vol. 22, p. 147-162, 2005.

10. FILHO, L. J. R.; CARNEIRO, A. E. V. Governança eletrônica. Revista da Socie-dade da Informação, v. 1, n. 1, jan. 2008. Disponível em: < http:// sociedadedainformacao.com/Artigos/GOVERNAN \%C7A\%20ELETRONICA. pdf>. Acesso em: 30 Nov. 2015.

11. FREY, K. Governança eletrônica: experiências de cidades européias e algumas lições para países em desenvolvimento. Revista IP - Informática Pública, Belo Horizonte, v. 2, p. 31-48, maio 2000.

12. FREY, K.; REZENDE, D. A. Administração estratégica e governança eletrônica na gestão urbana. Revista Eletrônica de Gestão de Negócios, v. 1, n. 1, p. 51-59, abr./jun. 2005. 
13. FUNG, A.; WRIGHT, E. O. Deepening democracy: innovations in empowered participatory governance. Politics and Society, n. 29, p. 5-42, 2000.

14. GOMES, W. A democracia digital e o problema da participação civil na decisão política. Fronteiras - estudos midiáticos. VII(3): p. 214-222, setembro/dezembro 2005.

15. JAEGER, P. T. Deliberative democracy and the conceptual foundation of electronic government. Government Information Quartely, n. 22, p. 702-719, 2005.

16. JARDIM, J. M. A construção do e-gov no Brasil: configurações político-informacionais. In: ENCONTRO NACIONAL DA CIÊNCIA DA INFORMAÇÃO, 5., 2004, Salvador, BA. Anais. Salvador: CINFORM, 2004. Disponível em: <http://www. cinform.ufba.br/v_anais/artigos/josemaria jardim.html>. Acesso em: 17 out. 2015.

17. LOGOLINK. Relatório de Pesquisa: Governança eletrônica local - Perspectivas latinoamericanas. Instituto Pólis, 2010 (Mimeo).

18. NAVARRO, Z. O orçamento participativo de Porto Alegre - 1989-2002: um conciso comentário crítico. In: SANTOS B. S. (Org.). Democratizar a democracia: os caminhos da democracia participativa. Rio de Janeiro: Civilização Brasileira, 2005.

19. OLIVEIRA, F. M. de; VAZ , J. C.; CARTY, W. Internet use and citizen participation in local government: Ipatinga's interactive participatory budgeting. Disponível em: http://docs.google.com/gview?a=v\&q=cache\%3Aljd897qOeCEJ\%3Aashinstitute.harvard.edu \%2Fash\%2Flpatinga_ITG_Case. pdf+op+ipatinga+vaz\&hl=pt-BR\&pli=1. Acesso em: 20 dez. 2015.

20. PEEL, D. Utilizando as tecnologias digitais para a ampliação da participação pública no planejamento. In: CUNHA, M. A.; FREY, K.; DUARTE, F. (org.). Governança local e as tecnologias da informação e comunicação. Curitiba: Champagnat, 2009.

21. PEIXOTO, T. Beyond Theory: e-Participatory Budgeting and its Promises for eParticipation. European Journal of Practice, n. 7, Mar 2009.

22. PESSI, P. E-OP: uma nova prática comunicativa do Orçamento Participativo em Porto Alegre. 2003. Dissertação (Mestrado) - Universidade Federal do Rio Grande do Sul, Porto Alegre, 2003.

23. PORRAS, J. I. Internet, política y democracia local. Documentación Social, n. 133, p. 53-76, 2004. Disponível em: <http://www.esterkaufman.com.ar/sitios/kauf-man/publicaciones/Ar tInternetyDemocraciaLocal.pdf>. Acesso em: 15 out. 2015.

24. PRADO, O.; LOUREIRO, M. R. Governo eletrônico e transparência: avaliação da publicização das contas públicas das capitais brasileiras. Revista Alcance, v.13, n.3, p. 355-372, set.-dez. 2006.

25. REZENDE, D. A.; FREY, K. Administração estratégica e governança eletrônica na gestão urbana. eGesta - Revista Eletrônica de Gestão de Negócios, v. 1, n. 1, p. 51-59, abr.-jun. 2005. Disponível em: http://www.buscalegis.ufsc.br/revistas/index.php/buscalegis/article/viewArti cle/30681.

26. RIBEIRO, M. M. Como o governo eletrônico pode aumentar a transparência das compras governamentais? In: CONGRESSO CONSAD DE GESTÃO PÚBLICA, 2008, Brasília.

27. RUEDIGER, M. A. Governo eletrônico ou governança eletrônica: conceitos alternativos no uso 
das tecnologias de informação para o provimento de acesso cívico aos mecanismos de governo e da reforma do Estado. In: CONCURSO DE ENSAYOS Y MONOGRAFIAS DEL CLAD SOBRE REFORMA DEL ESTADO Y MODERNIZACIÓN DE LA ADMINISTRACION PÚBLICA, 21., 2002, Caracas. Anais. Caracas, 2002.

28. SAMPAIO, R. C. Diferentes modos de participação: alguns impactos da introdução da internet no Orçamento Participativo de Belo Horizonte. Comunicação \& Política, v. 27, p. 51-78, 2009.

29. VAZ, J. C. Desafios para a inclusão digital e governança eletrônica. Disponível em: <file:///C:/Users/20131015020342/Downloads/808.pdf>. Acesso em: 11 Dez. 2015.

30. . Limites e possibilidades do uso de portais municipais para promoção da cidadania: a construção de um modelo de análise e avaliação. Tese (doutorado) - EAESP/FGV, São Paulo. 2003

31. Governança eletrônica: para onde é possível caminhar? Boletim Dicas, Instituto Pólis. Disponível em: http://www.polis.org.br/uploads/745/745.pdf Acesso em: 2 Nov. 2015.

32. WAMPLER, B.; Avritzer, Leonardo; Navarro, Zander. Orçamento Participativo: uma explicação para as amplas variações nos resultados. Is inovação democráticas no Brasil. 2003.

33. YIN, Robert K. Estudo de caso: Planejamento e Métodos. 5. ed. Porto Alegre: Bookman, 2015.

34. YIN. R. K. 3 ed. Porto Alegre: Bookman, 2005. 